This is an electronic reprint of the original article. This reprint may differ from the original in pagination and typographic detail.

Author(s): Zhang, Boyang; Vos, Marita

Title: $\quad$ Social media monitoring: aims, methods, and challenges for international companies

Year: $\quad 2014$

Version:

Please cite the original version:

Zhang, B., \& Vos, M. (2014). Social media monitoring: aims, methods, and challenges for international companies. Corporate Communications: An International Journal, 19(4), 371-383. https://doi.org/10.1108/CCIJ-07-2013-0044

All material supplied via JYX is protected by copyright and other intellectual property rights, and duplication or sale of all or part of any of the repository collections is not permitted, except that material may be duplicated by you for your research use or educational purposes in electronic or print form. You must obtain permission for any other use. Electronic or print copies may not be offered, whether for sale or otherwise to anyone who is not an authorised user. 


\title{
Social media monitoring: Aims, methods, and challenges for international companies
}

Boyang Zhang and Marita Vos, University of Jyväskylä

\begin{abstract}
Purpose - This paper seeks to clarify the aims, monitoring methods, and challenges of social media monitoring from the perspective of international companies. Trends in the literature are also investigated.
\end{abstract}

Design/methodology/approach - Based on a systematic literature review, 30 key articles from 2008 to 2012 were further analysed.

Findings - International companies need real-time monitoring software, expertise and dynamic visualization to facilitate early detection and prognoses supporting strategy making. This is a costly affair, prompting questions about return on investment. A recent trend in the research literature concerns the development of models describing how issues spread in social media with the aim of facilitating prognoses.

Research limitations/implications - The online databases used comprised refereed peer-reviewed scientific articles. Books were not included in the search process.

Practical implications - Because information spreads fast in social media and affects international companies, they need to identify issues early, in order to monitor and predict their growth. This paper discusses the difficulties posed by this objective.

Originality/value - Social media monitoring is a young research area and research on the topic has been conducted from many different perspectives. Therefore, this paper brings together current insights geared towards corporate communication by international companies.

Keywords: Social media, monitoring, international companies

Paper type: Research paper 


\section{Introduction}

This research paper aims at clarifying social media monitoring from the perspective of international companies. A systematic literature review was used to seek current insights on the methods used, and so illuminate not only the benefits but also the difficulties attached to the monitoring process.

With the development of science and technology, social media have come to exert great impact on commercial value (Adkins \& Lury, 2011; Thackeray, Neiger, Hanson, \& McKenzie, 2008). With high numbers of users, issues spread fast via social media (Lawrence et al., 2010; Zailskaite-Jakste \& Kuvykaite, 2012). This affects international corporations which, in order to maintain profitable relationships, need to identify issues early and monitor and predict their growth (Banerjee \& Agarwal, 2012; Coombs \& Holladay, 2012). The concept issue refers to how a topic is seen and discussed (Meriläinen \& Vos, 2013). Issues are social constructions (Hallahan, 2001) and may be perceived differently by different public groups. Company issues can be very diverse, and include, for example, criticism of the social responsibility of a firm in the public debate. Early prognosis of issue interaction could prevent financial or reputational losses. Therefore, monitoring social media interaction has become vitally important for international companies.

Social media offer an interactive platform for dialogue between users, including individuals and companies. Companies have different objectives for being active in social media, which serves not only early identification of issues but also interaction with stakeholders. In order to attract attention to the brand and accelerate the development of online trade, international companies have adapted social corporate marketing (Illia \& John, 2012) and the use of media marketing channels (Dekay, 2012). Their attention has shifted from passive one-way communication on the company's home page to more vivid two-way corporate communication (Booth \& Matic, 2011). As global and complex platforms, social media exert a profound impact on international companies with businesses all over the world, as acknowledged in corporate communications. The increasing activity in social media also calls for methods to follow online consumer interaction regarding the brand. Consequently, researchers have shown increasing interest in what is measured and how, when monitoring and tracking interaction in social media.

Monitoring includes listening, interpreting, and taking action on what people are saying or otherwise conveying (Rappaport, 2010). Monitoring can be defined as 
finding out what is expressed online, for example about a company's products and services, and should be a default social media function (Divol, Edelman, \& Sarrazin, 2012). Observing and evaluating interaction in social media needs an open mind. The results of social media monitoring provide a 'snapshot' of a discussion at a particular moment or show developments in a discussion over time. The term 'tracking' refers to following the development of a particular phenomenon that has been identified in the course of the monitoring process. While the monitoring of social media interaction has obvious advantages, it also incurs considerable costs. These factors provide the rationale for this study, which aims at clarifying the methods of monitoring used, and their benefits and challenges for international companies. A company can use the results of monitoring to decide how to intervene in social media. To do this effectively requires good data. This study focuses on what may facilitate or hinder the creation of such data.

\section{Method}

This exploratory paper is based on a systematic literature review of peer-reviewed journals. It aims at elucidating the use of social media monitoring or tracking and what benefits and difficulties this may entail for international companies. In the databases of EBSCOhost and ProQuest, after several tryouts, the key words "social media” and [company or organization] and [monitoring or prognosis or metrics or tracking or analytics] were selected. The search spanned a 10-year period, 2003-2013, although the earlier years yielded no results, and was restricted to peer-reviewed papers. The search results were copied in RefWorks software for further analysis. After checking the title and abstract to see if they matched the keywords, and confining the search to papers in English, 38 articles remained. These articles were read thoroughly with the further selection criterion that they discussed monitoring or tracking of social media interaction by companies or other organizations. This resulted in a sample of 30 articles, published during the years 2008-2012 (these titles are marked * in the reference list). 


\begin{tabular}{|c|c|c|}
\hline Keywords & Database & First result \\
\hline \multirow{2}{*}{$\begin{array}{l}\text { “social media” } \\
\text { and [company or } \\
\text { organization] }\end{array}$} & EBSCOhost & $\begin{array}{l}58 \\
(28.02 .2013)\end{array}$ \\
\hline & ProQuest & $\begin{array}{l}55 \\
(01.03 .2013)\end{array}$ \\
\hline \multirow{3}{*}{$\begin{array}{l}\text { and [monitoring } \\
\text { or tracking or prognosis } \\
\text { or metrics } \\
\text { or analytics] }\end{array}$} & $\begin{array}{l}\text { Total } \\
\text { (after removing } \\
\text { duplicates) }\end{array}$ & $\begin{array}{l}93 \\
(03.03 .2013)\end{array}$ \\
\hline & $\begin{array}{l}\text { After checking abstracts } \\
\text { and title }\end{array}$ & 38 \\
\hline & $\begin{array}{l}\text { Final sample after } \\
\text { reading the articles }\end{array}$ & 30 \\
\hline
\end{tabular}

Table 1 Search results per database

After reading the articles the following research questions were posed.

RQ1: What aims are considered important for the monitoring or tracking activities addressed in the literature?

RQ2: What methods are mentioned in the literature for monitoring and tracking social media interaction from an organizational perspective?

RQ3: What challenges does social media monitoring pose for international companies?

RQ4: What trends can be seen in the literature concerning the monitoring of social media interaction from an organizational perspective?

To facilitate the thematic analysis of the articles in the sample, a data extraction table was made. The articles were reread to build a summary of fragments relevant to one of the four questions. The overview spanned 20 pages, and included mention of the year of publication and a code indicating if an article was based on empirical data and what kinds of social media were discussed. This approach was designed to clarify the aims and methods of monitoring, including its benefits and challenges. Furthermore, trends in the literature were noted. 


\section{Findings}

The findings are presented below. In each section, the findings are presented and summarized.

\subsection{Aims of monitoring or tracking activities}

The aims of monitoring or tracking activities were addressed in 17 articles. These aims were categorized into 4 groups, which are described in the following sections.

\section{Listen and interact via social media}

Companies are active in monitoring social media to gather information from customers and collaborate through networks (Billington \& Billington, 2012). Online discussion in social media offers more personalized information on products and services. Users can post positive experiences on the brand's home page, but also complaints when encountering dissatisfaction, and expand the discussion when problems are not resolved, which calls for social media monitoring. Chen (2010) characterized social media markets as conversations with value-creating conversations consumers. Various examples were discussed in the literature, including the "Ford Fiesta Movement" campaign, where fun experiences were posted in Twitter, Facebook, MySpace and YouTube (Palmer \& Koenig-Lewis, 2009) in order to attract the attention of potential customers.

\section{Brand protection}

In the current social media boom, enterprises commonly open official brand homepages in social media (Kumar \& Mirchandani, 2012; Pehlivan, Sarican, \& Berthon, 2011; Petty, 2012; Wang, 2012). Next to the official entrepreneurial homepages, such as the official McDonald's Facebook page, there are also unauthorized fan sites. These have increased in number, testifying to the eagerness of influencers to express their opinions, but also leaving users uncertain as to whether these messages are sponsored, affiliated or endorsed (Petty, 2012). While user-generated communication and consumer-generated media enrich the communication experience (Palmer \& Koenig-Lewis, 2009), crises in social media pose significant threats to normal business activities and corporate reputation. Coombs and Holladay (2012) analyse the Kindle crisis case, showing that online apology and reputation repair contributes to the effectiveness of the crisis response strategy. 
In the process of social media monitoring, analyses of the online environment and the competition are simultaneously indispensable (Zailskaite-Jakste \& Kuvykaite, 2012). Competitors may, for example, arrange negative opinions in blogs and social networks. Therefore, Petty (2012) has pointed out that a monitoring management framework is imperative to protect the brand by following how it is mentioned.

\section{Brand values}

The increased importance of the blogosphere has evoked a need to track current discourse on the brand and predict future buzz (Lawrence et al., 2010). The observation of blog data may help forecast the spread patterns of bloggers (Banerjee \& Agarwal, 2012). The activities of a pool of influential individual users, known as 'influencers', have exerted a profound impact on marketing strategy and, therefore, marketers seek to identify influencers in order to either reinforce them or, at least, gain the benefit of an early warning for brand management (Kumar \& Mirchandani, 2012).

Companies seek to promote the attention given to the brand and its values in social media and transfer interested users to their linked product or service websites. For example, many firms, such as Coca-Cola, disseminate brand information in Twitter (Rinaldo, Tapp, \& Laverie, 2011). This may strengthen the position of the brand. Online promotion activities through content innovation can win fans to generate sustainable positive word of mouth (Kumar \& Mirchandani, 2012). Digitalized information is uploaded by users, and all of this user-created content is interrelated with branding (Munar, 2011). The effects of online brand activities are supported by research, including monitoring and, as in the case of Toyota when it faced quality issues and recalls in early 2010, public opinion surveys (Fan, Geddes \& Flory, 2013).

\section{Scholarly aims}

Identifying issues early and monitoring their development may help predict the growth of a relevant issue (Luoma-aho \& Vos, 2010). Similarly, the subsequent citation of tweets has been investigated to see if this can predict behaviour in social media (Eysenbach, 2012), and researchers have suggested manipulating tweets to study their dissemination (Rinaldo, Tapp, \& Laverie, 2011). Dissemination of messages in social media, e.g. through followers and re-tweets, draws attention to an issue, which can be studied from the perspective of agenda-setting theory (Meriläinen \& Vos, 2011). Furthermore, the detection and monitoring of web-based interpersonal conversation has been proposed in order to develop more effective health communication interventions (Bouman, Drossaert, \& Pieterse, 2012). 


\section{To sum up}

Monitoring and tracking make it possible for companies to evaluate online interaction that affects the brand, and see how these results relate to the company's values and mission. Furthermore, the effects of communication strategies can be followed. In general, analysis of the aims for monitoring and tracking activities mentioned in the literature reveals, that it is considered important to listen, interact, influence and reflect on social media interaction from a stakeholder perspective (See Figure 1).

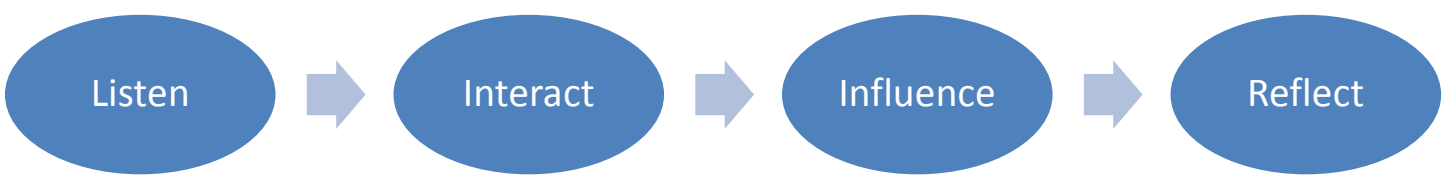

Figure 1. Aim of monitoring or tracking activities

International companies need to position themselves clearly in the online environment, as well as to pick up and interpret feedback from social media discourse. This creates a basis for interaction that, as a next step, may benefit the brand image online. The literature emphasizes brand protection and brand values. Furthermore, reflection is critical in order to better understand the impact of the interaction and evaluate one's own activities online in order to improve the company's online practices.

\subsection{Methods of monitoring or tracking}

In the sample, 25 articles discussed specific monitoring or tracking methods, the feasibility of these methods, and their limitations, such as limited research capability.

Social media are a diverse group, comprising "new sources of online information such as SNS (Social Network Sites), blogs, chat-rooms, rating websites, video and photo sharing websites and podcasts, created and used for purposes about issues including products and brands” (Michaelidou, Siamagka \& Christodoulides, 2011, p. 1154). The diversity of social media is also reflected in what is measured and how. Rappaport (2010) mentions various categories of solutions to the problem of monitoring social media that are currently on offer, including search engines and media-monitoring offerings, text-analytics software companies that use semantic analysis, full-service listening platform vendors and private branded communities. Below we report insights on the methods used, including search, semantic and sentiment analysis, and analysis of spread patterns. 


\section{Keyword Search}

Companies can set the topics to be monitored in a way that suits their products, management features and brand images. As Rappaport says (2010, p. 198), "Choosing a listening solution depends, naturally, on its fit with organizational or brand objectives for listening, the listening budget, and how the listening responsibility is staffed”. Search includes general search engines, those of a particular social medium, such as Twitter Search, but also real-time dashboard overviews of social media such as provided by Addict-o-matic. Below, we illustrate how these were used in the literature.

For example, Google offers a search engine for social media icons or references (Zailskaite-Jakste \& Kuvykaite, 2012). Other authors mention, e.g. Google Trends, which shows timeline-based search sources (Michaelidou et al., 2011), and Social Mention, which provides real-time search and analysis in the social media context (Zailskaite-Jakste \& Kuvykaite, 2012). To search tweet citations, one can use various metrics such as scientometrics, infodemiology and infometrics (Eysenbach, 2012). While the monitoring can include various sources, such as Google Blog Search, Addict-o-matic, and Twitter Search to intercept the latest messages, this needs to be complemented by an analysis of the online environment and competitors (Zailskaite-Jakste \& Kuvykaite, 2012).

Petty (2012, p. 759) notes that even search can be tricky, "While a firm can always use search engines to perform regular searches for use of its brand name, such searches will most readily uncover uses that spell the name correctly”. Nevertheless, performing a regular search, using search engines to track a brand name in order to protect it and uncover comments, is useful and can be outsourced (Petty, 2012).

As mentioned before, text-based key phrases can be computed in traditional information retrieval. Analytics are based on keyword searches or machine learning and can capture, for example, hot topics for market benefits. However, Lawrence et al. (2010) caution that such analytics may bring problems of classification that need to be solved in different ways in the currently available search engines. As Luoma-aho and Vos (2010, p. 322) note, "In this new environment, social media reputation as well as search engine reputation is more important than before".

\section{Thematic and sentiment analysis}

Semantic classifications are used to gain a better understanding of social media discourse. Often the aim is to obtain comprehensive and accurate information at an early stage, before issues can spread in social media. Researchers have developed various ways of monitoring conversations so as to be able to prepare early responses to 
potential crises. One approach is to identify themes and how they are discussed in social media, while another approach is to focus on the sentiments expressed, for example, by identifying positive and negative phrases related to the brand. Here, we give examples of both approaches as found in the literature.

Bouman et al. (2012) utilized search engines that automatically collect conversations from social media to then explore relevant themes discussed within these conversations. Their method, titled 'Mark My Words', was developed to track information dissemination and the effects of health communication interventions. To capture sentiment trends, machine-based algorithms were exploited to track shifts in opinions by capturing positive and negative phrases (Nadeem, 2012). Similarly, the statistical online application FanBuzz Visualizer was developed to visualize the intensity of fan discourse about music artists (Hanna et al., 2011). The analysis of themes discussed and sentiments can also be combined, as in research conducted to follow comments on products and campaigns through real-time visualizations and dashboards, and simultaneously run sentiment analyses (Divol, Edelman, \& Sarrazin, 2012). Unfortunately, many authors do not disclose the precise monitoring methods used in their studies, largely leaving the monitoring process a black box, particularly in the case of commercial tools.

Software is used to analyse large quantities of data. This may be complemented by manual textual analysis and coding, as in the case of samples where the amount of data is relatively small and where a qualitative approach is adapted. A manual textual analysis was chosen for a qualitative analysis of online agenda setting on human rights spanning various months (Meriläinen \& Vos, 2011). Similarly, coding categories were manually established to qualitatively evaluate company crisis response strategies in the online environment (Coombs \& Holladay, 2012).

\section{Analysis of spread patterns}

Monitoring is also used to analyze how messages spread in social media. One approach is to find causal relations and follow the impact of social media interventions. Another approach is to follow the spread pattern to be able to predict its development.

Conversations in social networking sites with the most potential for generating and influencing purchasing decisions were monitored using the analytical tools available on the sites to analyse the spread and impact of social media messages (Kumar \& Mirchandani, 2012). Ticketing systems can be tied to social networks to investigate online customer influence on sales, for example when online retailers allow customers to sign in with social network IDs. 
The analytical applications may include both coding and text mining. For example, Software SAS Enterprise Text Miner and NVivo were applied in word frequency analyses and concept link studies to see if the source of consumer-generated advertisements online positively or negatively influenced consumer reactions (Pehlivan et al., 2011). Furthermore, in order to measure the impact of citations, creating tweets to see who will follow has provided empirical evidence of the impact of mentioning scientific articles in Twitter (Rinaldo, Tapp, \& Laverie, 2011).

Relatively few articles investigated how the spread of messages in social media could be predicted. Some messages go viral and spread widely in social media, while others show a short life cycle. Chen (2010) constructed a market intelligence analysis framework to make prognoses on how social media discourse may develop. In addition, Banerjee and Agarwal (2012) introduce a theory to model collective behaviour in social media, using data about blogs and comparing the spread pattern to the movements of ants in a swarm.

\section{Combination of methods}

When semantic analysis vendors fail to satisfy all the needs of a company, many look for additional services such as agency services for planning, executing and consulting solutions. Such services are offered by, what Rappaport (2010) calls, "Full-Services Listening-Platform Vendors”. These new integral services have sprung from a variety of businesses, from creative and media agencies to customer relationship agencies, consultancies and technology vendors, combining various skills, including data analytics, planning and creative work in collaboration with support agencies (Hipperson, 2010). Full service social media agencies may add much value to companies but the costs can be high, especially for small or medium size entrepreneurs (Rappaport, 2010).

Next to the use of a combination of methods, an integral approach can also be seen, as in researching and using various social media. For example, Meriläinen and Vos (2011) compare the content of Facebook posts and Twitter messages when discussing organizational multi-platform approaches. It should be noted that social media are very diverse. Therefore, researchers may differentiate between, for example, friendship-driven and interest-driven social networking tools (Rinaldo et al., 2011). However, social media evolve over time: for example, while Facebook initially facilitated the exchange of photos and short stories with close acquaintances, currently most companies and brands are also represented. An integral approach, taking into account the changing characteristics and use of social media, is called for. Since social media form a dynamic environment, monitoring methods also need to develop fast. 


\section{Summary}

To conclude, the methods identified in the literature included keyword search, thematic and sentiment analysis, analysis of spread patterns and combinations of methods (See Figure 2).

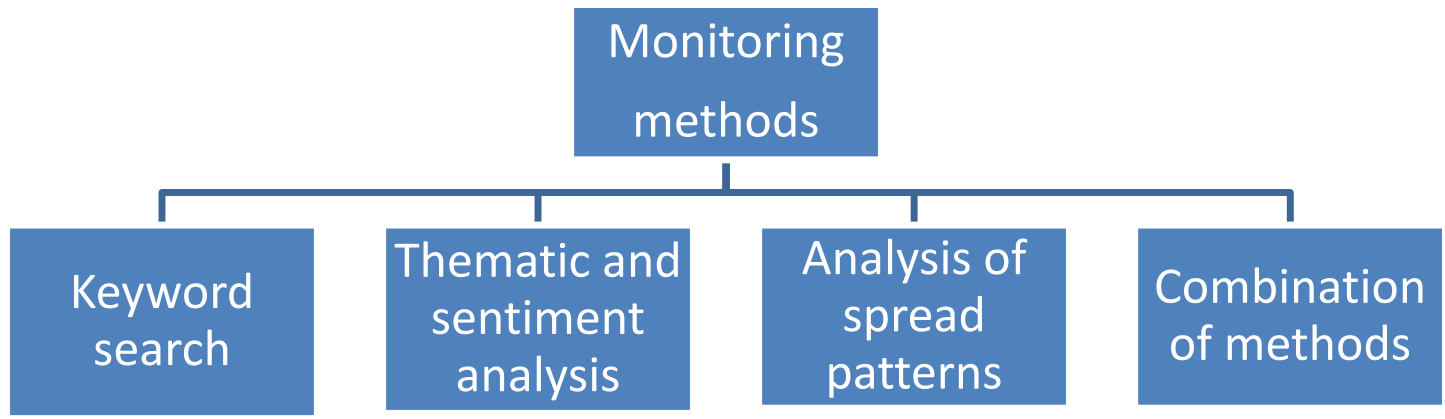

Figure 2. Monitoring methods for tracking activities

In order to make thorough inquiries in social media, it seems that next to knowledge of these methods a spirit of inquiry that will lead to their further development is also needed.

\subsection{Challenges}

As presented earlier, social media have unique features with respect to interaction and dissemination of information across time and space. In this section, we gather insights from the literature on the challenges related to social media monitoring. Almost all of the articles in the sample mentioned challenges in this area.

Many researchers agree that the most important characteristic of social media is that users can generate, edit and disseminate information themselves, compared to the traditional media, where the mode of propagation is mainly one-way (Bouman et al., 2012; Davenport, Barth, \& Bean, 2012; Divol et al., 2012; Fogel, 2010; Kumar \& Mirchandani, 2012; Meriläinen \& Vos, 2011; Pehlivan et al., 2011; Rappaport, 2010; Thackeray, Neiger, Hanson, \& McKenzie, 2008; Zailskaite-Jakste \& Kuvykaite, 2012). Although the advantages of monitoring social media may be obvious, at the same time, companies also face challenges in their monitoring and tracking activities. 


\section{Complicated and changing methods}

According to Adkins and Lury (2011) the fast development of social media and social media-related monitoring methods also imposes various constraints. These mainly relate to methodology. Discerning what information to track and developing the appropriate metrics to determine analytics is challenging (Fogel, 2010; Fernando, 2010). For example, user experiences are difficult to measure (Palmer \& Koenig-Lewis, 2009). In addition, inclusion of different local languages is demanding (Munar, 2011), and this is especially important to international companies. New methods are constantly appearing on the market, many of which may be a black box to companies, making it hard to compare and keep track of what is on offer.

\section{High costs and unclear return on investments}

Some authors also point to the high costs involved for the company (e.g. Fogel, 2010). Besides, there is also scepticism about the return on investment in online activities, as sales do not always follow user referrals (Henry, 2011). Similarly, it is also difficult to estimate the impact of social media monitoring on sales (Fogel, 2010; Divol et al., 2012). It may be easy to monitor influencers' conversations (Kumar \& Mirchandani, 2012), and responding at a personal level is seen as a positive form of social media engagement (Cervenková, Šimek et al., 2011; Divol et al., 2012; Hanna et al., 2011). However, a single post has the power to destroy an influencer's reputation and social credibility in a few keystrokes (Wang, 2012). So, mistakes made may weigh heavily.

\section{Ethical constraints}

Online influencers can be identified and companies can inform and encourage them to talk about the brand. However, recruiting and incentivizing key users as influencers (as suggested by Kumar \& Mirchandani, 2012) may lead to a loss of credibility. In addition, some countries have rules on the disclosure of online influencers. This is not related to the monitoring activity itself but rather to the interventions chosen by the company based on the monitoring results.

According to Wang (2012), social media initiatives should not just aim at commercial objectives but also create social value for the participants. Ethical constraints may also be applied to protect privacy, as social media users may not expect to be monitored by companies. Other ethical constraints relate to the use of metrics. For example, in the future funding might be granted to authors on the basis of the number of tweets their articles have received. However, the number of tweets about a scholarly article may indicate its popularity rather than the value of its scientific content, making 
this a clear case for imposing ethical constraints on the use of tweet metrics (Eysenbach, 2012).

\section{Problematic interpretation}

An organization can analyse monitoring data simply for the purpose of better understanding consumer communities (Hipperson, 2010). For example, detecting brand favourability in social media can help interpret the views of different target groups (Rappaport, 2010). However, consumer groups may interpret messages sent from a company in diverse ways (Zailskaite-Jakste \& Kuvykaite, 2012). Hence, data interpretation may be problematic, and big data are also known to include big mistakes. "Just as prices were a coordinating mechanism in traditional markets, today dialogue and interpretation have become the primary coordinating mechanism in the marketplace” (Chen, 2010). For this reason, (mis)interpretations of monitoring metrics can be critical.

In sum

To conclude, four elements were found to be major challenges in monitoring social media: methodological constraints, high costs and unclear return on investment (ROI), ethical constraints and possible misinterpretation of metrics (see Figure 3).

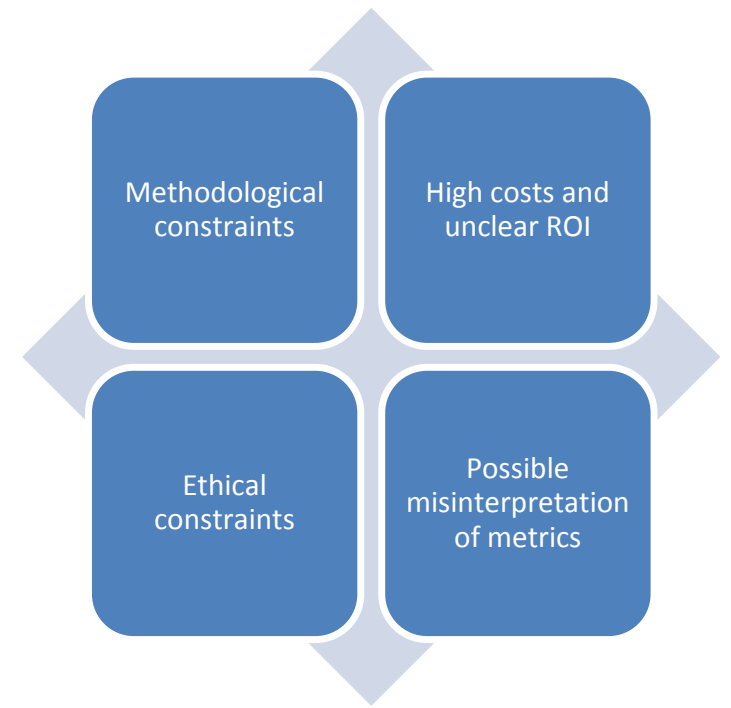

Figure 3 Main Challenges in Monitoring social media

In order to meet these challenges, companies need both a good understanding of the process of monitoring and to look for solutions appropriate to their situation. They also must set clear objectives for social media monitoring. What currently are viewed as challenges may become opportunities when companies find better or faster solutions 
than their competitors.

\subsection{Trends in the literature}

None of the articles reflected explicitly on trends in the literature, but the overview of the 30 articles in the sample shows some interesting trends. Figure 4 clearly shows an increase of interest in the topic.

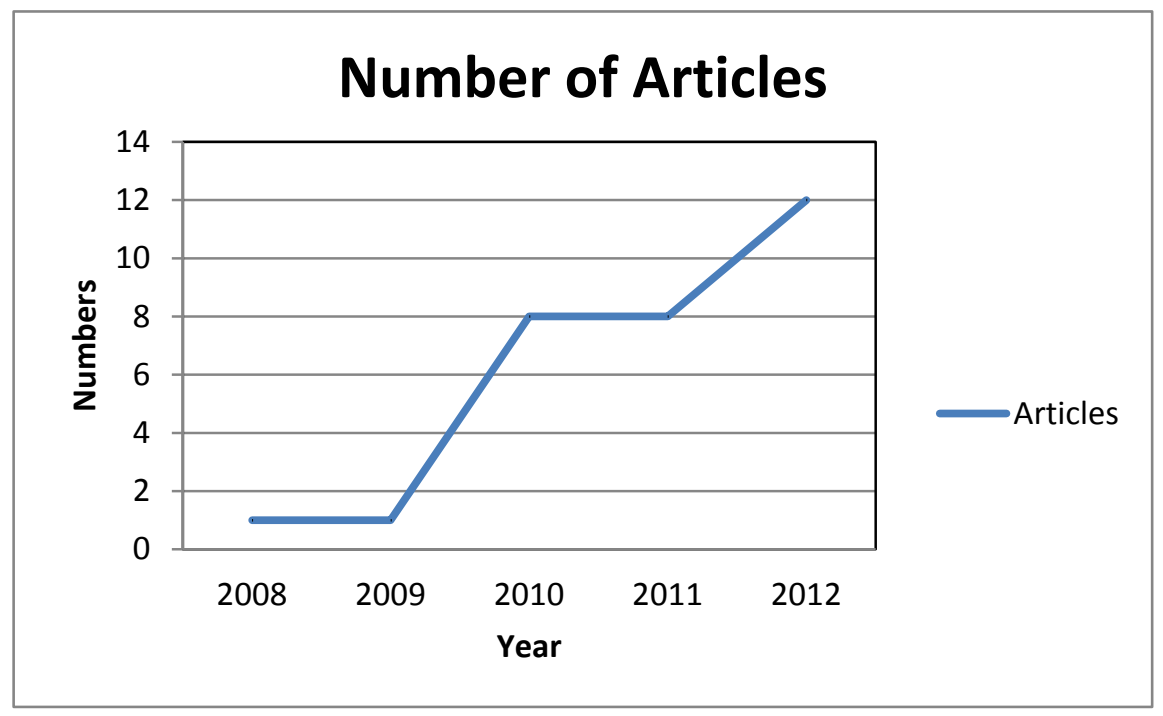

Figure 4. Number of articles on monitoring social media per year

Before 2008, no articles were found that matched the search keywords. The sample comprised one article each in 2008 and 2009, eight articles in 2010 and the same in 2011, while 12 were published in 2012.

Clustering of the topic in particular journals is not yet evident. Apparently the topic has relevance for a wide variety of journals. Corporate Communications had two titles while all other titles in the sample were published in diverse journals focusing on, for example, business, tourism, marketing, health, communication, finance, sociology, and information technology.

Of the sample of 30 articles, 25 included empirical data, while the others were theoretical papers or essays discussing practices and literature. Most attention was given to analytics and the pivotal role of monitoring. The most commonly discussed social media tools in the articles were Facebook (17 articles), Twitter (13 articles), and YouTube (4 articles). In 10 articles, both Facebook and Twitter were addressed. A recent direction taken in the research literature concerns the development of models of the dissemination of issues in social media to enable prognoses to be made (e.g. Banerjee \& Agarwal, 2012). 


\section{Conclusion and discussion}

Social media have apparently allowed users and companies to experience the magic of interaction. Traditional advertisements in TV or magazines are not able to incorporate user experiences, and the performance of feedback is lower than in social media. The unique characteristics of social media allow companies to capture information with immediacy (Billington \& Billington, 2012). Therefore, the new integral services for social media monitoring need to provide output in real time (Hipperson, 2010), for example, sending alerts when words of interest are noted (Rappaport, 2010).

By following the brand in real time, companies can react to possible negative information at an early stage before this becomes widely disseminated. Such intervention may effectively reduce the number of crises. Next to threats, opportunities for reputation gain could also be spotted. Based on monitoring social media, some early forms of business intelligence have also been developed to use monitoring and tracking data to make prognoses of, for example, users' preferences, consumption habits and purchasing power (Chen, 2010).

The purpose of this paper is to clarify social media monitoring from the perspective of international companies, by conducting a structured literature review and further analysing 30 key articles in refereed journals. International companies are paying increasing attention to the value of online communication. They listen, interact, influence and reflect on online discussion, to gain a better understanding of customer values and needs, and support their mission in international and local social media.

The methods of monitoring social media are as diverse and dynamic as social media interaction itself. Here, they were grouped into four categories, including word search, thematic and sentiment analysis, analysis of spread patterns, and combination of methods. Various difficulties accompanying monitoring activities were identified in the literature. These include methodological constraints, as it is challenging to realize the precise metrics needed, at the same time taking into account interaction in various languages on different and changing social media platforms. In addition, monitoring activities come at a high cost and their return on investment is not yet clear. Furthermore, there are ethical constraints related to the measurement of online interaction and difficulties in the interpretation of the metrics. However, there is much at stake, as being active without having any monitoring methods at hand may feel like groping around in the dark. 


\section{Implications for practice}

In the online environment customers are increasingly able to communicate among themselves, while companies have to compete for attention with information coming from a wide range of peer groups (Palmer \& Koenig-Lewis, 2009). Taking the negative and positive consequences of social media discourse into account through timely search collection, collation and analysis reports, and the establishment of supervision by a public opinion feedback mechanism, international companies could accelerate their activities in monitoring and analysing the online environment, and so be better equipped to participate in online communication. By keeping track of social media interaction and the results of their own participation, companies can develop the competencies needed to operate in the online environment. Depending on the objectives they have set for their social media interaction, some companies may need to acquire precise information on the return on investment of such activities, whereas other companies consider being active online necessary at all times, including continuous improvement of their communication on the basis of qualitative feedback and quantitative metrics. The challenges of monitoring also bring opportunities with them, which some companies may be better placed to take advantage of than others, and thereby gain competitive advantage in the social media environment.

\section{Limitations and future research}

The number of articles found in this study was small, as this is a young research area. This also means that its results could become outdated relatively soon. Therefore, to look ahead, we also examined trends in the literature. A clear increase in the numbers of publications occurred 2009. The monitoring methods used in the articles were seldom introduced in detail, indicating that authors may not want to disclose these and that reviewers, alas, do not seem to insist on the sharing such details. In addition, the ethical problems relating to monitoring need to be addressed.

Future research could address monitoring methods in greater detail, and in addition to a focus on a single method, a broader view on metrics, e.g. by comparing different approaches, could also be attempted. In addition, gaining knowledge on the effects of social media activities, even if insufficient to yield a full picture of return on investment, would be useful. This could be done in case studies (e.g. Coombs \& Holladay, 2012; Fernando, 2010) but also in an experimental context (as shown by e.g. Bouman et al, 2012; Eysenbach, 2012). Furthermore, studies investigating how issues spread in social media could be undertaken, e.g. in case studies of spread patterns as well as conceptual work (such as Banerjee \&Agarwal, 2012; Chen, 2010). 
The future research directions chosen should take into account that developments in social media are user-driven, and that business models reflect trends set by users and user communities. How to identify the characteristics and behaviours of users for each social media site is an interesting topic, but while the survival conditions of each site vary widely, all need to meet user needs. Therefore, the changing needs of stakeholders need to be at the centre of online monitoring activities. Monitoring social media activities in the online environment, including the performance of international companies, looks set to remain a priority of the research agenda for some time to come. 


\section{References}

Adkins, L., \& Lury, C. (2011), “Introduction: Special measures”, The Sociological Review, Vol. 59 Supp.2, pp. 5-23. *

Banerjee, S., \& Agarwal, N. (2012), “Analyzing collective behavior from blogs using swarm intelligence”, Knowledge and Information Systems, Vol. 33 No. 3, pp. 523-547. *

Billington, M. G., \& Billington, P. J. (2012), “Social media tools for leaders and managers”, Journal of Leadership, Accountability and Ethics, Vol. 9 No. 6, pp. 11-19. *

Booth, N., \& Matic, J. A. (2011), "Mapping and leveraging influencers in social media to shape corporate brand perceptions", Corporate Communications: An International Journal, Vol. 16 No. 3, pp. 184-191.

Bouman, M. P. A., Drossaert, C. H. C., \& Pieterse, M. E. (2012), "Mark my words: The design of an innovative methodology to detect and analyze interpersonal health conversations in web and social media”, Journal of Technology in Human Services, Vol. 30 No. 3-4, pp. 312-326. *

Cervenková, E., Šimek, P., Vogeltanzova, T.,\& Stoces, M. (2011), "Social networks as an integration tool in rural areas -- Agricultural Enterprises of the Czech Republic", Agris On-Line Papers in Economics \& Informatics, Vol. 3 No. 1, pp. 53-60. *

Chen, H. (2010), “Business and market intelligence 2.0, Part 2”, IEEE Intelligent Systems, Vol. 25 No.2, pp. 74-82. *

Coombs, W. T., \& Holladay, S. J. (2012), “Amazon.com's Orwellian nightmare: Exploring apology in an online environment”, Journal of Communication Management, Vol. 16 No. 3, pp. 280-295. *

Davenport, T. H., Barth, P., \& Bean, R. (2012), “How 'big data' is different. (cover story)”, MIT Sloan Management Review, Vol. 54 No. 1, pp. 43-46. *

Dekay, S. H. (2012), "How large companies react to negative Facebook comments”, Corporate Communications: An International Journal, Vol. 17 No.3, pp. 289-299.

Divol, R., Edelman, D., \& Sarrazin, H. (2012), “Demystifying social media”, McKinsey Quarterly, 2012 No. 2, pp. 66-77.*

Eysenbach, G. (2012), "Can tweets predict citations? Metrics of social impact based on Twitter and correlation with traditional metrics of scientific impact", Journal of Medical Internet Research, Vol. 14 No. 1, pp. 410-411. *

Fan, D., Geddes, D. \& Flory, F. (2013). “The Toyota recall crisis: Media impact on Toyota's corporate brand reputation” Corporate Reputation Review, Vol. 16 No. 2, 
pp. 99-117.

Fernando, I. (2010), “Community creation by means of a social media paradigm”, Learning Organization, Vol. 17 No. 6, pp. 500-514. *

Fogel, S. (2010), “Issues in measurement of word of mouth in social media marketing”, International Journal of Integrated Marketing Communications, Vol. 2 No. 2, pp. 54-60. *

Hallahan, K. (2001), "The dynamics of issues activation and response: An issues processes model” Journal of Public Relations Research, Vol. 13 No. 1, pp. 27-59.

Hanna, R., Rohm, A., \& Crittenden, V. L. (2011), “We’re all connected: The power of the social media ecosystem”, Business horizons, Vol. 54 No.3, pp. 265-273. *

Henry, S. E. (2011), "Social networking for the equipment finance industry: Divine or a distraction?”, The Journal of Equipment Lease Financing (Online), Vol. 29 No. 1, pp. 1D-7D. *

Hipperson, T. (2010), "The changing face of data insight - And its relationship to brand marketing”, Journal of Database Marketing \& Customer Strategy Management, Vol. 17 No.3, pp. 262-266.

Illia, L., \& John, M. T. B. (2012), “Corporate communication and corporate marketing”, Corporate Communications: An International Journal, Vol. 17 No. 3, pp. 415-433.

Kumar, V., \& Mirchandani, R. (2012), “Increasing the ROI of social media marketing”, MIT Sloan Management Review, Vol. 54 No. 1, pp. 55-61. *

Lawrence, R., Melville, P., Perlich, C., Sindhwani, V., Meliksetian, S., Hsueh, P.-Y., \& Liu, Y. (2010), “Social media analytics”, OR-MS Today, Vol. 37 No. 1, pp. 26. *

Luoma-aho, V., \& Vos, M. (2010), “Towards a more dynamic stakeholder model: acknowledging multiple issue arenas”, Corporate Communications: An International Journal, Vol. 15 No. 3, pp. 315-331.

Meriläinen, N., \& Vos, M. (2011), "Human rights organizations and online agenda setting”, Corporate Communications: An International Journal, Vol. 16 No. 4, pp. 293-310.

Meriläinen, N. and Vos, M. (2013), Framing issues in the public debate: the case of human rights, Corporate Communications an International Journal, Vol. 18 No. 1, pp.119-134.

Michaelidou, N., Siamagka, N. T., \& Christodoulides, G. (2011), "Usage, barriers and measurement of social media marketing: An exploratory investigation of small and medium B2B brands”, Industrial Marketing Management, Vol. 40 No. 7, pp. 1153-1159. * 
Munar, A. M. (2011), “Tourist-created content: rethinking destination branding”, International Journal of Culture, Tourism and Hospitality Research, Vol. 5 No. 3, pp. 291-305. *

Nadeem, M. (2012), “Social customer relationship management (SCRM): How connecting social analytics to business analytics enhances customer care and loyalty?”, International Journal of Business and Social Science, Vol. 3 No. 21, pp. 88-102. *

Palmer, A., \& Koenig-Lewis, N. (2009), “An experiential, social network-based approach to direct marketing”, Direct Marketing, Vol. 3 No. 3, pp. 162-176. *

Pehlivan, E., Sarican, F., \& Berthon, P. (2011), “Mining messages: Exploring consumer response to consumer- vs. firm-generated ads”, Journal of Consumer Behaviour, Vol. 10 No. 6, pp. 313-321. *

Petty, R. D. (2012), “Using the law to protect the brand on social media sites: A three "M"s framework for marketing managers”, Management Research Review, Vol. 35 No. 9, pp. 758-769. *

Rappaport, S. D. (2010), “Listening solutions”, Journal of Advertising Research, Vol. 50 No.2, pp. 197-213. *

Rinaldo, S. B., Tapp, S., \& Laverie, D. A. (2011), “Learning by tweeting: Using Twitter as a pedagogical tool”, Journal of Marketing Education, Vol. 33 No.2, pp. 193-203. *

Thackeray, R., Neiger, B. L., Hanson, C. L., \& McKenzie, J. F. (2008), “Enhancing promotional strategies within social marketing programs: Use of Web 2.0 social media”, Health Promotion Practice, Vol. 9 No. 4, pp. 338-343. *

Wang, H. (2012), "Six P's of youth social media from a young consumer's perspective”, Young Consumers, Vol. 13 No. 3, pp. 303-317. *

Zailskaite-Jakste, L., \& Kuvykaite, R. (2012), "Implementation of communication in social media by promoting studies at higher education institutions”, Engineering Economics, Vol. 23 No. 2, pp. 174-188. * 